Postgraduate Bosowa University Publishing (PBUP)
Indonesian Journal of Business and Management
e-ISSN: $2460-3767 \quad p$-ISSN: $2656-6885$
Inttps://postgraduate.universitasbosowa.ac.id/index.php/jbm
JOURAL

\title{
PENGARUH LINGKUNGAN KERJA, MOTIVASI KERJA DAN DISIPLIN KERJA TERHADAP KINERJA PEGAWAIDI KANTOR KECAMATAN CENRANA KABUPATEN MAROS
}

\author{
The Influence of Work Environment, Work Motivation, and Work Discipline on Employee Performance \\ at the Cenrana District Office, Maros Regency
}

\author{
Herlinda $^{1}$, Firman Menne ${ }^{2}$, Seri Suriani ${ }^{2}$ \\ ${ }^{1}$ Magister Manajemen Universitas Universitas Bosowa \\ ${ }^{2}$ Program Studi Manajemen Program Pascasarjana Universitas Bosowa \\ Email: herlinda.herlinda777@gmail.com
}

Diterima: 02 Januari 2021/Disetujui: 02 Juni 2021

\begin{abstract}
ABSTRAK
Penelitian ini bertujuan adalah untuk (1) Mengetahui pengaruh lingkungan kerja terhadap kinerja pegawai, (2) Mengetahui pengaruh motivasi kerja terhadap kinerja pegawai, (3) Mengetahui pengaruh disiplin kerja terhadap kinerja pegawai. Penelitian ini dilakukan di kantor Kecamatan Cenrana Kabupaten Maros. Penelitian ini menggunakan data primer dan sekunder, jumlah sampel yaitu 30 orang. Pendekatan kuantitatif merupakan jenis pendekatan dalam penelitian ini dan dianalisis menggunakan metode regresi linear berganda dengan olah data SPSS 21 untuk membuktikan tiga hipotesis. Hasil penelitian ini membuktikan bahwasemua variable bebas secara bersama-sama atau simultan berpengaruh signifikan terhadap variabel terikat yaitu kinerja pegawai. Berdasarkan hasil penelitian ini, diketahui bahwa lingkungan kerja, motivasi kerja dan disiplin kerja berpengaruh signifikan terhadap kinerja pegawai di kantor Kecamatan Cenrana Kabupaten Maros. Diartikansemakin baik suasana dalam lingkungan kerja, serta adanya motivasi kerja dan disiplin kerja tinggi akan memberikan dampak baik bagi pegawai dalam menjalankan tugas dan tanggung jawabnya sehingga akan berpengaruh terhadap kinerja pegawai yang lebih baik.
\end{abstract}

Kata Kunci: Lingkungan Kerja, Motivasi Kerja, Disiplin Kerja, Kinerja Pegawai

\begin{abstract}
This study aims to (1) determine the influence of work environment on employee performance, (2) determine the influence of work motivation on employee performance, (3) determine the influence of work discipline on employee performance. This research was conducted at the head office of cenrana district, Maros Regency. The data used in this study were primary and secondary data, with the total sample of 30 people. This study used a quantitative approach and analyzed using multiple linear regression analysis with the help of SPSS 21 data processing to prove three hypotheses. The results of this study prove that the independent variables jointly or simultaneously have a significant effect on the dependent variable, employee performance. Based on the results of this study, it is known that the work environment, work motivation and work discipline have a significant effect on employee performance in the Cenrana District Office, Maros Regency. Thus it can be interpreted that the better the atmosphere in the work environment, as well as the existence of work motivation and high work discipline, the more likely this will have a good impact on employees in carrying out their duties and responsibilities so that will also affect their performance.
\end{abstract}

Keywords: Work Environment, Work Motivation, Work Discipline, Employee Performance. 


\section{PENDAHULUAN}

Sumber daya manusia menjadifaktor yang terdapat di setiap organisasi maupun perusahaan, dengan adanya sumber daya manusia suatu perusahaan atau organisasi tentu membawa dampak dalam perkembangan maupun daya saing dalam perubahan zaman saat ini. Dalam upaya pembangunan suatu perusahaan dan instansi, sumber daya manusia mempunyai peranan sangat penting dalam proses untuk mencapai suatu tujuan. Organisasi adalah wadah setiap orang untuk dapat memberikan aspirasinya demi mencapai kemajuan organisasi. Kegiatan dalam organisasi disebut dengan pengorganisasian. Organisasi pemerintah mempunyai suatu peran yang penting dalam melaksanakan kegiatan pemerintahan dan memberikan pelayanan pada publik secara keseluruhan yang menjadi wujud dari pelaksanaan otonomi daerah.

Organisasi adalah sistem, rangkaiankomponenkomponen secara keseluruhan bekerja sama. Dari tiap komponenmenjadi sub sistemdan mempunyai kekayaan sistem bagi dirinya sendiri. Adahubungansangat melekatdiantara kinerja individu dan kinerja organisasi. Artinya, jika kinerja para pegawai baik besar kemungkinanpada kinerjadalam organisasiakan baik juga. Makaorganisasi seharusnya dapat dengan benar mementingkanfaktor sumber daya manusianya.

Pengelolaan sumber daya manusia tentunya yang terpenting yaitukinerja pegawai.Organisasi harus melakukan penilaian kinerja pegawai dalam pelaksanaannya. Kinerja yaitu jawaban apakah tujuan organisasi berhasil atau tidak. Hal ini dapat dilihat dari seberapa jauh pegawai menjalankan tugas dan tanggung jawabnya. Menurut Mangkunegara (2009) kinerja adalah hasil kerja dari segi kualitas dan kuantitas yang dicapai oleh pegawai dalam menjalankan tugas berdasarkan tanggungjawab yang dibebankan kepadanya. Kinerja baik dapat dilihat salah satunya jikapegawai dapat memberikan pelayanan baik kepada publik.Oleh karena itu, organisasi setidaknya harus selalu memperhatikan lingkungan kerja, motivasi kerja dan disiplinkerjanya sehingga kinerja pegawai tetap konsisten.

Lingkungan kerja yaitu segala sesuatu di sekitar pegawai yangbisa mempengaruhi dirinya untuk melaksanakan tugas yang diberikan. Fasilitas kerja yang termasuk dalam lingkungan kerja memberikan dampak dalam menciptakan suasana kerja kondusif dan positif. Oleh karena itu, instansi atau perusahaan harus menyiapkan lingkungan kerja yang mumpuni seperti kenyaman dalam tata kantor, penerangan yang cukup serta lingkungan yang bersih. Lingkungan yang baik dapat membuat pegawai merasa nyaman dalam menjalankan tugas dan tanggung jawabnya dengan semanagat serta mampu meningkatkan kinerja kerja para pegawai kantor Kecamatan Cenrana Kabupaten Maros.

Motivasi dari para pegawai selain lingkungan kerja tak kalah penting di dalam meningkatlan kinerja karyawan. Motivasi yaitu adanya hal membangkitkan spirit atau semangat kerja, sehingga tinggirendahnya motivasi kerja pada pegawai dapat menentukan kinerja.
Apabila pegawai mempunyai motivasi yang kuat, tentunya ia akan bekerja keras, mempertahankan langkah serta mempunyai perilaku yang terkendali kepada sasaran - sasaran penting. Artinya, seorang pegawai dengana motivasi tinggi dalam pekerjaannya akan memperoleh kinerja yang baik pula. Berdasarkan data dalam sasaran kerja pegawai di Kantor Kecamatan Cenrana, hasil interview dengan bagian kepegawaian di Kantor Kecamatan Cenrana ditemukan yaitu motivasi pegawai masih kurang. Penilaian kinerja yang didasarkan pada Sasaran Kerja Pegawai (SKP) termasuk pegawai mendekati usia pensiun. Hal ini disebabkan pada pegawai yang usia tidak produktif ini diantaranyaterdapat kesulitanuntuk penggunaan teknologi terkini, yang berbasisinternet dan komputer. Dan tidak menutup kemungkinan juga hal tersebut dialami oleh beberapa pegawai lainnya, sedangkan pengelolaan teknologi informasi sebagian besar kegiatan ataupun data yang dioleh menggunakan sistem komputerisasi.

Selain itu, disiplin juga merupakan factor yang mempengaruhi kinerja. Menurut Singodimedjo (2016), disiplin ialah usaha-usaha dilakukan dalammenghasilkan keadaan dalam lingkungan kerjatertib, berdaya guna dan berhasil guna melalui suatu sistem pengaturan tepat. Tanpa disiplin ada, maka semuaaktivitas yang dilakukan hasilnya akan kurang memuaskan dan tidak sesuaiyang diinginkan. Dan itu bisa menimbulkantujuan instansi atau organisasitidak tercapai serta terhambatnya program organisasi yang telah direncanakan.

Dalam mencapai tujuan organisasi disiplin menjadi langkah awal dari setiap kesuksesan. Disiplin mempunyai tujuan agar setiap pegawai dalam organisai dengan sukarela mentaati dan mematuhi tanpa paksaan setiap tata tertib. Disiplin kerja baik bisa ditunjukkan dengan tingginya kesadaran pegawai dalam mentaati serta menjalankan peraturan serta tata tertib berlaku, besarnya perasaan tanggungjawab terhadap setiap tugasnya, serta meningkatkan efisiensi dan kinerja setiap pegawai. Kedisiplinan merupakan fungsi operatif manajemen sumber daya manusia yang penting karena jika disiplin pegawai dalam instansi semakin baik akan menciptakan pegawai berkualitas. Tanpa disiplin tinggi maka sebuah instansi atau perushaan tersebut akan mengalami kesulitandalam memperoleh kesuksesan yang diinginkan.

Tinggi rendahnya sumber daya, dapat diketahui dari kinerja aparat pemerintah dan kualitas pelayanan diukur sejauh mana aktivitas dan efisiensi dalam pelayanan terhadap publik atau masyarkat. Kinerja dan kualitas sumber daya adalah nilai-nilai yang harus diaplikasikan kepada semua pegawai agar menyadari mereka adalah pelayanan masyarakat.

Kantor KecamatanCenrana adalah lembaga instansi pemerintahan dan dipimpin seorang Camat dengan bantuan beberapa saksi dalam melaksanakan pemerintahan diwilayah Kecamatan Cenrana Kabupaten Maros sebagai organisasi pelayanan masyarakat. Kondisi pada kantor kecamatan tersebut terlihat masih kurang pada kualitas pelayanan dan diduga masih kurang memberikan kepuasan kepada masyarakat. Adapun dari 
beberapa masyarakat ada yang menyatakan bahwa pegawai kantor kecamatanbelum memberikan pelayananmaksimal, seperti halnyauntuk pengurusan surat yang membutuhkan waktucukup lama.

Selain itu, segi kecepatanpelayanan yang diberikan masih tergolong lamban dan melebihi waktu yang ditetapkan sehingga beberapa pekerjaan tidak dapat terselesaikan tepat waktunya. Tentunya dari masalah yang ada tersebut harus segera diperbaiki sehingga tidak memberi hambatan terhadap visi serta misi pada Kantor Kecamatan Cenrana. Berdasarkan latar belakang penelitian tersebut yang dipaparkan, sehingga peneliti tertarik mengadakan penelitiandengan judul "Pengaruh Lingkungan Kerja, Motivasi Kerja, dan Disiplin Kerja terhadap Kinerja Pegawai di Kantor Kecamatan Cenrana Kabupaten Maros".

\section{METODE}

Jenis penelitian pada penelitian ini merupakan jenis penelitian kuantitatif. Penelitian kuantitatif ialah jenis penelitian yang menggunakan pendekatan deduktifinduktif. Pendekatan yang berawal dari kerangka teori, gagasan para ahli, atau pemahaman peneliti berdasarkan pengalaman, lalu dikembangkan menjadi permasalahan beserta pemecahan dan diajukan untuk memperoleh pembenaran atau penilaian dalam bentuk dukungan data empiris di lapangan. Dan penelitian ini menggunakan kuisioner langsung dengan teknik analisis data yaitu menggunakan pendekatan regresi linear berganda.

Populasi yaitu wilayah generalisasi terdiri dari objek dan subjek yang memiliki kualitas serta karakteristik tertentu dan diterapkan dari penulis untuk dapat dipelajari dan ditarik kesimpulan (Sugiyono, 2007). Dalam penelitian ini populasi sebanyak 30 pegawai Kantor Kecamatan Cenrana Kabupaten Maros, dan seluruhjumlah populasi diambil menjadi sampel dalam penelitian ini(sampel jenuh).

Pengumpulan data penelitian menggunakan teknik kuesionerlangsung diberikan kepada responden terkait di Kantor Kecamatan Cenrana. Adapun skala pengukuran menggunakan skala Likert, dalapm pengukuran hasil dari jawaban responden yaitu dengan lima tingkatan pilihan jawaban yang mempunyaipoin berbeda-beda. Selain itu, data juga diperoleh dengan teknik dokumentasi dan kepustakaan.

\section{HASIL DAN PEMBAHASAN}

\section{a. Karakteristik Responden}

Pengumpulan data yaitu dengan memberikan kuesioner ke setiap pegawai di kantor Kecamatan Cenrana Kabupaten Maros. Berdasarkan jenis kelamin menunjukkan jika responden pada penelitian ini kebanyakanberjenis kelamin perempuan yaitu 16 (53\%) responden sedangkan berjenis kelamin laki-laki hanya 14(47\%) responden.. Dan juga responden dalam penelitian ini mempunyai tingkat golongan dimana dengan golongan IVb 1 orang $(3 \%)$, responden dengan golongan IVa 2 orang (7\%), responden golongan IIId 4 orang $(13 \%)$, responden golongan IIIb 4 orang $(13 \%)$, responden golongan IIIa 4 orang (13\%), responden golongan IId 2 orang (7\%), responden golongan IIc 3 orang $(10 \%)$, responden golongan IIb 7 orang $(23 \%)$ dan yang terakhir responden dengan golongan IIa sebanyak 3 orang (10\%). Adapun responden berdasarkan umur sebagian besar yaitu responden yang berumur sekitar 4149 tahun 13 orang (43\%) kemudian responden berumur 50-58 tahun sebanyak 10 orang (33\%) sedangkan responden berumur sekitar 32-40 tahun hanya sebanyak 7 orang $(23 \%)$.

\section{b. Uji Validitas Dan Reliabilitas Instrumen}

Pemeriksaan diperoleh nilai dari uji validitas yang menunjukan perbedaan disetiap indikator-indikator atau instrumen pengukuran dalam penelitian ini. Berdasarkan tabel diketahui bahwa semua indikator memilki rhirung > rtabel 0,362 yang berarti valid. Untuk mengukur reliabilitas dengan menggunakan alat pengukuran Cronbach's Alphadengan kriterianya adalahAlpha hitung> daripada koefisien Cronbach's Alpha yakni 0,60 sehingga data yang diperoleh mempunyai reliabilitas baik.

\section{Pembahasan}

Hasil penelitian menunjukkanyakni terdapat pengaruh lingkungan kerja terhadap kinerja pegawai di kantor Kecamatan Cenrana Kabupaten Maros. Hal ini terbukti dari hasil statistik uji t yaitu 2,166 nilai signifikansi 0,041 $<0,05$. Berdasarkan data diatas,dapat di tarik kesimpulan variable lingkungan kerja berpengaruh terhadap kinerja pegawai di Kantor Kecamatan Cenrana, dimana jika lingkungan kerjanya baik diharapkan akan meningkatkan kinerja pegawainya.

Hasil penelitian menunjukkan yakni ada pengaruh motivasi kerja terhadap kinerja pegawai di kantor Kecamatan Cenrana Kabupaten Maros. Hal ini terbukti dari hasil statistik uji t yaitu 1,883 nilai signifikansi 0,033 $<0,05$. Dan dilihat dari hasil kuesioner penelitian dengan item pernyataan tertinggi ialah pada item kesatu yaitu hasil prestasi kerja pegawai yang telah dicapai selalu mendapat apresiasi dan pujian dari atasan dan dinilai positif oleh pegawai lainnya, tentu hal ini memberikan dampak sangat baik sehingga dapat lebih meningkatkan motivasi kerja para pegawai sehingga dapat di tarik kesimpulan bahwa variable motivasi kerja berpengaruh terhadap kinerja pegawai Kantor Kecamatan Cenrana, dimana jika motivasi kerja dari pegawai tinggi maka akan meningkatkan kinerja pegawainya.

Hasil penelitian menunjukkan yakni adaa pengaruh disiplin kerja terhadap kinerja pegawai pada kantor Kecamatan Cenrana Kabupaten Maros. Hal ini terbukti dari hasil statistik uji t 1,746 nilai signifikansi $0,026<0,05$. Dilihathasil kuesioner penelitian dengan item pernyataan tertinggi ialah pada item kelima yaitu pegawai kantor Kecamatan Cenrana selalu menjalankan dan melaksanakan pekerjaan atas perintah dari pimpinan. Yang dapat diartikan bahwa selama ini para pegawai telah melaksanakan tugas sesuai dengan tupoksinya dan hal ini 
tentu sangat membawa dampak yang baik bagi pihakpihak lain termasuk untuk masyarakat.

Berdasarkan hasil penelitian tersebut menunjukkan yakni ada pengaruh variable lingkungan kerja, motivasi kerja dan disiplin kerja terhadap kinerja pegawai di kantor Kecamatan Cenrana Kabupaten Maros. Karena diperoleh perhitungan uji $\mathrm{F}$ yaitu $\mathrm{F}$ hitung 6,353> $\mathrm{F}$ tabel sebesar 2,98 signifikansinya $0,000<0,05$. Hal ini menunjukkan yakni secara stimulanatau bersama-sama semua variabel bebas yaitu lingkungan kerja, motivasi kerja dan disiplin kerja berpengaruh signifikan terhadap variabel terikat yaitu kinerja pegawai dengan kesimpulan $\mathrm{H}_{1}$ diterima. Oleh karena itu, jika lingkungan kerja, motivasi kerja serta disiplin kerja pegawai terus ditingkatkan maka tentunya bisa meningkatkan kinerja pegawai dan pelayanan pun bisa lebih optimal.

\section{KESIMPULAN DAN SARAN}

\section{a. Kesimpulan}

Berdasarkan hasilpenelitiandi kantor Kecamatan Cenrana Kabupaten Maros sehingga ditarik kesimpulan, yakni Lingkungan kerja mempunyai pengaruh signifikan terhadap kinerja pegawai di kantor Kecamatan Cenrana Kabupaten Maros. Artinyadapat diinterpresentasikan jika semakin baik suasana di lingkungan kerja membawa dampakpositif pula bagi para pegawai dengan adanya rasa aman dan nyaman yang dirasakan pegawai di kantor Kecamatan Cenrana. Motivasi kerja mempunyai pengaruh signifikan terhadap kinerja pegawai di kantor Kecamatan Cenrana Kabupaten Maros. Artinya, dapat diinterpresentasikan semakin baik motivasi kerja para pegawaihal ini akan membawa dan memberikan dampak yang baik terhadap kinerja pegawai dalam menjalankan tugas dan tanggung jawabnya dalam bekerja dan melayani masyarakat di Kecamatan Cenrana. Disiplin kerja memilikipengaruh yang signifikan terhadap kinerja pegawai di kantor Kecamatan Cenrana Kabupaten Maros. Artinya, dapat diinterpresentasikan bahwa semakin baik disiplin kerja para pegawai membawa dan memberi dampak yang baik juga terhadap kinerjaa pegawai di kantor Kecamatan Cenrana, yang mana kedepannya akan membawa nilai positif di masyarakat jika dapat dilakukan dengan sepenuh hati dan diterapkan dengan baik dengan penuh ketulusan. Adapun variabel disiplin kerja adalah variabel paling mempunyai pengaruh terhadap kinerja pegawai di Kantor Kecamatan Cenrana dalam penelitian ini, dengan melihat hasil yang didapatkan di kuesioner dapat disimpulkan pegawai di kantor Kecamatan Cenrana mempunyai disiplin kerja yang baik yang membawa kinerja baik pula di Kantor Kecamatan Cenrana.

b. Saran

Saran-saran yang bisa penulis berikan, ialah Atasan kantor Kecamatan Cenrana (Camat), diharapkan untuk dapat menciptakan dan meningkatkan lingkungan kerja yang kondusif kepada pegawai dan memberikan pengawasan lebih dalam peraturan yang lebih ketat sehingga dapat memaksimalkan kinerja pegawai yang ada agar tidak menimbulkan kesalahan. Atasan kantor
Kecamatan Cenrana (Camat), selalu mengontrol hubungan antar sesama pegawai dan diharapkan silaturahmi yang baik dapat berjalan antar pegawai dengan adanya kegiatan yang bisa dilakukan diluar jam kerja seperti kegiatan ibadah. Penelitian berikutnya diharapkan dapat mengembangkan dan menggunakan variabel lainnya agar memperoleh penjelasan lebih baik lagi daripada penelitian saat ini.

\section{DAFTAR PUSTAKA}

Alex S, Nitisemito. 2002. Wawasan Sumber Daya Manusia:Pustaka Utama Grafiti. Jakarta.

Arikunto, Suharsimi. 2006. Prosedur Penelitian Suatu Pendekatan Praktik: Rineka Cipta. Jakarta.

Bambang,Prasetyo. 2006. Metode Penelitian Kuantitatif: Teori dan Aplikasi. Raja Grafindo Persada.

Davis, J. H., Schoorman, F. Davi., dan Donaldson, Lex. 1997. Towards a Stewardship Theory of Management. Academy of Management Review :221, 20-47.

Fathoni. 2006:126. Manajemen Sumber Daya Manusia. Bandung.

Frasmita, Nita. 2017. Penerapan Disiplin Siswa di Sekolah Menengah Swasta (SMAS) Kartika XX2 Kendari. Repository Perpustakaan IAIN Kendari.

Ghozali, Imam. 2011. Aplikasi Analisis Multivariate dengan Program SPSS. Badan Penerbit Universitas Diponegoro. Semarang.

Gomes, F.C. 2003.Manajemen Sumber Daya Manusia. Yogyakarta.

Handoko, T.Hani, 2003:252. Manajemen Personalia dan Sumber Daya Manusia. Yogyakarta, BPFEYogyakarta.

Hasibuan, Malayu S.P. 2007:95. Manajemen Sumber Daya Manusia Perusahaan. PT. Bumi Aksara. Jakarta.

Hasibuan, Malayu S.P. 2008:157. Manajemen Dasar, Pengertian dan Masalah. PT. Bumi Aksara. Jakarta.

Hermawan, Asep. 2005. Penelitian Bisnis (Paradigma Kuantitatif). Grasindo. Jakarta .

Hidayat, Zainul \& Taufiq, Muchamad. 2012. Pengaruh Lingkungan Kerja dan Disiplin Kerja serta Motivasi Kerja terhadap Kinerja Karyawan Perusahaan Daerah Air Minum (PDAM) Kabupaten Lumajang. Jurnal WIGA Vo. 2 No. 1

https://id.wikipedia.org/wiki/Lingkungan(diakses Februari 2021)

JohnH. Jackson, Robert L. Mathis. (2006:378). Manajemen Sumber Daya Manusia (Human Resource Management). Book Thesis. Terbitan: Salemba Empat.

Jusmaliani. 2014.Pengelolaan Sumber Daya Insani. PT Bumi Aksara. Jakarta .

Kantor Camat. 2020. Kecamatan Cenrana. Kabupaten Maros 
Kisworo, Bagus. 2012. Hubungan Antara Motivasi, Disiplin, Dan Lingkungan Kerja Dengan Kinerja Pendidik dan Tenaga Kependidikan Sanggar Kegiatan Belajar Eks Karisidenan Semarang Jawa Tengah. Tesis : UNY.

Kurniawan, Aris. 2021. Pengertian Lingkungan Menurut

Para

Ahli.

https://www.gurupendidikan.co.id/pengertian-

lingkungan/ (diakses Februari 2021)

Mangkunegara, Anwar Prabu. 2009. Evaluasi Kinerja Sumber Daya Manusia. Penerbit Refika Aditama: Bandung.

Martono, Nanang. 2011. Metode Penelitian Kuantitatif. Analisis Isi dan Analisis Data Sekunder. Raja Grafindo Persada. Jakarta.

Nawawi, Hadari. 2006.Evaluasi Dan Manajemen Kinerja Di Lingkungan Perusahaan Dan Industri. Yogyakarta.

Novyanti Sagita, Joyce. 2015. Pengaruh Motivasi Kerja, Lingkungan Kerja dan Disiplin Kerja terhadap Kinerja Pegawai pada BAPPEDA Provinsi Sulawesi Tengah. Jurnal Katalogis Vol. 3 No. 1 Hal 105-115 